University of Nebraska - Lincoln

DigitalCommons@University of Nebraska - Lincoln

\title{
Supporting the Visual-Cognitive Sciences by Exploring the Application of Photographic Composition to Visual Scene Displays
}

\author{
Kevin Pitt \\ University of Nebraska-Lincoln, kevin.pitt@unl.edu \\ John McCarthy \\ Ohio University, mccarthj@ohio.edu \\ Adrienne R. Pitt \\ University of Nebraska - Lincoln, apitt@unl.edu
}

Follow this and additional works at: https://digitalcommons.unl.edu/specedfacpub

Part of the Special Education and Teaching Commons

Pitt, Kevin; McCarthy, John; and Pitt, Adrienne R., "Supporting the Visual-Cognitive Sciences by Exploring the Application of Photographic Composition to Visual Scene Displays" (2020). Special Education and Communication Disorders Faculty Publications. 219.

https://digitalcommons.unl.edu/specedfacpub/219

This Article is brought to you for free and open access by the Department of Special Education and Communication Disorders at DigitalCommons@University of Nebraska - Lincoln. It has been accepted for inclusion in Special Education and Communication Disorders Faculty Publications by an authorized administrator of DigitalCommons@University of Nebraska - Lincoln. 
Pitt, K., McCarthy, J., Pitt, A. (2020). Supporting the Visual-Cognitive Sciences by Exploring the Application of Photographic Composition to Visual Scene Displays. Accepted for presentation at the 2020 International Society for Augmentative and Alternative Communication (ISAAC) Conference, Cancun, Mexico. (convention cancelled). doi:10.32873/unl.dc.oth.003 https://doi.org/10.32873/unl.dc.oth.003

$\underline{\text { Title }}$

\title{
Supporting the Visual-Cognitive Sciences by Exploring the Application of Photographic Composition to Visual Scene Displays
}

Pitt, K., McCarthy, J., Pitt, A.

\begin{abstract}
AAC systems may be accessed via techniques such as touch, eye gaze and switch scanning, which are then translated into communication output. Traditionally, aided AAC displays utilize a grid layout, arranging communication items in a decontextualized manner. In contrast, visual scene displays (VSDs) utilize context rich images (e.g., photographs) that depict events and activities, presenting communication items in a contextualized manner (e.g., a toy in a toy chest; Wilkinson, Light, \& Drager, 2012). Recent research focusing on principles of the visualcognitive sciences has found that even small changes in how we present communication items in a grid or VSD format may positively influence communication outcomes (Light, Wilkinson, Thiessen, Beukelman, \& Fager, 2019). For instance, to support access to VSDs, research in the visual-cognitive sciences has identified that including meaningful interactions and human figures may engage individuals in scene content and promote VSD-based AAC success. AAC has a history of benefitting from bringing the perspectives of outside disciplines into conversations related to innovation and service delivery. Although digital photographs are easier than ever to obtain, there is still room for consideration of what makes a "good" photograph and capturing contextually rich photographs can make an enormous difference in the communication interactions these images support. Principles of photographic and art composition may support findings from the visual-cognitive sciences by limiting scene complexity through increased image structure and brining the viewers' attention to key scene elements (e.g., Peterson et al., 2003) that may be targeted during direct selection or scanning-based paradigms. Therefore, compositional factors may help ensure that an individual is not being distracted or possibly 'pulled out' of the scene during VSD viewing. Further, the use of compositional strategies in VSD design may provide avenues for the sorting and categorization of communication content on the AAC device, by allowing image sorting software to identify well composed images that are most likely to support communication success and social participation.
\end{abstract}

\section{Aims}

1) Explore compositional factors that may support VSD access by highlighting key scene elements. 
ISAAC 2020

2) Identify how these principles may be rapidly applied in a 'just in time' communication setting.

\section{Method}

Individuals with experience in art and photography completed a semi-structured interview discussing how the principles of composition can build on the visual-cognitive sciences literature to limit VSD complexity and highlight key scene elements by guiding image structure and use of color. Further, interviewees discussed what camera settings could be used to emphasize these compositional elements automatically. Following transcription, theme analysis will be analyzed using a data driven coding approach (Gibbs, 2008).

\section{Results}

Data collection is in progress at the time of proposal. Preliminary results indicate compositional principles such as 1) having the depicted meaningful activity fill a large amount of the image frame, 2) having leading lines which 'point' the viewer toward focal elements, and 3) considering the depth of field may support the identification of key scene elements. These results support findings of the visual-cognitive science in relation to AAC display design (e.g., individuals with developmental disabilities were not distracted by background elements in images where meaningful elements took up the majority of the scene; O'Neil et al., 2019). Compositional principles may be quickly applied by automatic camera functions such as portrait mode, and low aperture settings, which may be used to blur non-relevant scene information.

\section{Conclusion}

Results nay help guide VSD display design for both direct and indirect access methods, along with future forms of AAC access technology. Photographic examples of identified composition principles will be provided.

\section{Learning Outcomes}

Attendees will be able to discuss:

1) principles of the visual-cognitive sciences in relation to VSD design.

2) how principles of composition may inform VSD design.

3) the application of composition principles for VSD sorting.

\section{References}

Gibbs, G. (2008), Analyzing Qualitative Data. London: Sage Publications

Light, J., Wilkinson, K. M., Thiessen, A., Beukelman, D. R., \& Fager, S. K. (2019). Designing effective AAC displays for individuals with developmental or acquired disabilities: State of the science and future research directions. Augmentative and Alternative Communication, 35(1), 42-55.

O’Neill, T., Wilkinson, K. M., \& Light, J. (2019). Preliminary investigation of visual attention to complex AAC visual scene displays in individuals with and without developmental disabilities. Augmentative and Alternative Communication, 35(3), 240-250. 
ISAAC 2020

Peterson, B. (2003). Learning to See Creatively: Design, Color \& Composition in Photography (Ed. 3). Manhattan, NY: Amphoto.

Wilkinson, K. M., Light, J., \& Drager, K. (2012). Considerations for the composition of visual scene displays: Potential contributions of information from visual and cognitive sciences. Augmentative and Alternative Communication, 28(3), 137-147.

\section{Author details (150)}

Name

Institution

Address

Phone/fax/email

Biographical Sketch

Name

Institution

Biographical Sketch

Name

Institution

Address

Phone/fax/email
Kevin Pitt, PhD., CCC-SLP

University of Nebraska-Lincoln

357 Barkley Memorial Center, Lincoln, NE, 68583

Kevin.pitt@unl.edu

Kevin Pitt is an assistant professor in Communication Sciences and Disorders at the University of NebraskaLincoln, and PI of the AAC Translation (AACT) Laboratory. He is interested in translating the latest AAC access advancements such as brain-computer interfaces out of the laboratory setting by incorporating current clinical procedures, stakeholder input, and principles governing display design.

John McCarthy

Ohio University

John McCarthy is a Professor of Communication Disorders and Associate Dean of Research at Ohio University. He teaches courses on AAC, interprofessional education, preprofessional orientation, and introduction to communication disorders. His research includes improving computer interfaces and expanding the creative possibilities for children and young adults requiring AAC.

Adrienne Pitt, MSP, CCC-SLP

University of Nebraska-Lincoln

253H Barkley Memorial Center, Lincoln, NE 68583

402-472-3850; apitt@unl.edu 
ISAAC 2020

Biographical Sketch

Adrienne Pitt is a clinical instructor at the University of Nebraska-Lincoln as well as a doctoral candidate at the University of Kansas. Adrienne's clinical and research interests include developing assessment and intervention techniques for individuals with minimal verbal skills, including individuals with autism and other developmental disabilities. 